\title{
Indicative significance of the magnetic susceptibility of substrate sludge to heavy metal pollution of urban lakes
}

\author{
Yong Zhang*, Feiyan Huang \\ School of Resource, Environment and Safety Engineering, Hunan University of Science and Technology, \\ Xiangtan 411201 China
}

*Corresponding author, e-mail: 292278@qq.com

Received 2 Dec 2020

Accepted 12 Apr 2021

\begin{abstract}
Soil magnetic susceptibility has been widely used as an alternative index of soil heavy metal pollution because of its simple process, fast measurement, and good correlation with heavy metal. However, whether soil magnetic susceptibility can be used as an indicator of heavy metal pollution in urban water has not been studied in depth. In this study, 34 samples of substrate sludge and 39 soil samples were collected from lakes/ponds and their surrounding areas in Xiangtan City, Hunan Province. The magnetic susceptibility of individual samples was measured by a Bartington MS2 dual-frequency susceptibility meter. The results showed that the magnetic susceptibility of lake sediment and soil samples fluctuated between $11.60-160.77 \times 10^{-8} \mathrm{~m}^{3} / \mathrm{kg}$ and $5.33-107.17 \times 10^{-8} \mathrm{~m}^{3} / \mathrm{kg}$, respectively. The average magnetic susceptibility of lake sediment $\left(48.50 \times 10^{-8} \mathrm{~m}^{3} / \mathrm{kg}\right)$ was slightly higher than that of the surrounding soil $\left(41.75 \times 10^{-8} \mathrm{~m}^{3} / \mathrm{kg}\right)$. The magnetic susceptibility values of substrate sludge from small to large were Jiuhua Park, Juhuatang Park, and Yuhu Park. Many factors could affect lake sediment's magnetic susceptibility; and the main influencing factors could be: the shape of the lake, the strength of the current, the movement of the lake water, the aquatic ecosystem, the physical and chemical properties of the lake water, the intensity of human activities, the construction of buildings, and the types of factories and enterprises. More detailed studies and experiments are urgently needed to reveal the variation of laws and response mechanisms of sediment's magnetic susceptibility in urban lakes.
\end{abstract}

KEYWORDS: urban water, substrate sludge, magnetic susceptibility, heavy metal pollution

\section{INTRODUCTION}

In recent years, as a new technical approach, the medium's magnetic properties have been widely used to monitor and study the heavy metal pollution in soil and sediment [1-3]. The magnetic method has many advantages, such as rapidity, simplicity, low cost, no damages to samples, accessibility to fieldwork, and multi-parameter measurement $[4,5]$.

Many researches on heavy metal pollution, including tracing the source of pollutants, heavy metal pollution, land pollution classification, street dust, soil, automobile exhaust, showed that the magnetic parameters of media were intimately related to the degree of heavy metal pollution and could be used as an alternative indicator of heavy metal pollution [6-9]. Magnetic susceptibility is an essential magnetic parameter, which is the ratio of the magnetic intensity induced by the soil in the external magnetic field to the magnetic intensity [10-13].
The magnetic susceptibility can reflect the soil's magnetic strength and the content of ferromagnetic minerals in the soil, and it is closely related to the content of some heavy metals in the soil [14-17].

With the rapid development of China's economy, urbanization has been speeding up, and the number of urban populations has increased dramatically, leading to a series of urban pollution problems, such as the decline of urban air quality and water pollution. Urban waters play an essential role in the urban ecosystem. It can conserve water sources, regulate the local climate, and reduce pollutants' concentration in the atmosphere and soil, thus purifying the urban environment and playing an irreplaceable role in stabilizing and maintaining the urban ecological environment. Therefore, local governments and scientific researchers gradually began to pay attention to the maintenance, management, and rational use of urban waters [5]. Research on heavy metal pollution in urban waters has been imminent. The magnetic susceptibility had been 
applied to the study of heavy metal pollution in soil, but whether it can be used to study heavy metal pollution in urban lakes remains to be discussed.

Substrate sludge plays a vital role in the environment and ecology in aquatic ecosystems and is an essential pollution source (/sink) [18-20]. Once heavy metals pollute the water, most of them will be converted into a solid phase and deposited in the sediment. However, the substrate sludge's heavy metals are unstable, being rereleased and polluting the water body due to the changes of water environment, causing harm to the aquatic ecosystem. The substrate sludge is also the habitat and food source of benthic organisms in lakes. Benthic organisms can use these accumulated heavy metals both directly and indirectly [21-23]. However, heavy metals have distinct characteristics of bioconcentration and refractory degradation and will not migrate or be degraded by natural processes. Therefore, they will be preserved in sediment as an endogenous source of water pollution for a long time $[24,25]$. These heavy metals can return to the water body under specific physical and chemical conditions, causing secondary pollution and even endangering human health through environmental media or the food chain $[18,26,27]$.

Using the substrate sludge and topsoil of representative lakes and ponds in Xiangtan City as studied samples, this study aimed to find out: (i) the spatial variation of magnetic susceptibility of substrate sludge in urban lakes; and (ii) factors affecting magnetic susceptibility distribution of sediment in urban lakes. The findings were expected to provide a theoretical basis for urban water management and sustainable development.

\section{MATERIALS AND METHODS}

\section{Research area}

Xiangtan City $\left(27^{\circ} 21^{\prime}-28^{\circ} 05^{\prime} \mathrm{N}, 111^{\circ} 58^{\prime}-113^{\circ} 05^{\prime} \mathrm{E}\right)$ mainly composes of typical low-mountain-hilly landforms with Xiangjiang River, Lianshui River, and Juanshui River lying in the valley plain of Xiangjiang River. The City belongs to the subtropical humid monsoon climate with distinct seasons, abundant precipitation, high temperature in the summer, and cold winter. The annual average rainfall is over $1425 \mathrm{~mm}$. The precipitation concentrates from April to July, and the annual average temperature is $17.5^{\circ} \mathrm{C}$.

Because of its superior non-ferrous metal resources, mainly heavy industry has been developed in the studied area for a long time, leading to severe heavy metal pollution and ecological environment problems [28,29]. However, since 2015, Xiangtan City has gradually closed down its polluting factories and enterprises, vigorously rectified and improved the urban ecological environment, and eventually been nominated the fifth "National Civilized City" in 2017.

\section{Sampling, preparation, and analysis of soil samples}

In March 2018, samples were collected from Yuhu Park, Juhuatang Park, Jiuhua De Culture Park, Yaai Village Farmland, and Xiannvshan Farmland (Fig. S1). Firstly, the Google Map was used to determine the sampling range and the location of sampling points. When sampling in the field was performed, the sampling point's original position was adjusted according to the actual circumstances; and the coordinates of the actual sampling point were recorded by GPS. Finally, Google Map and Golden Software Surfer 11 were used to generate the schematic diagram of sampling points.

Surface soil samples around the lake were collected using a soil ring knife $(50.46 \times 50 \mathrm{~mm})$, and 39 samples were collected. By using a grab dredger, 34 samples of substrate sludge were also collected. All samples were sealed in polyethylene self-sealing bags and brought back to the laboratory for further testing.

Samples brought back to the laboratory were air-dried for a week. Then, litter, bricks, tiles, and garbage in individual samples were picked up, crushed, milled through 20 mesh sieves, uniformly mixed, and finally packed into polyethylene selfsealing bags. When testing, each sample was weighed, packed into $10 \mathrm{ml}$ special plastic boxes with plastic covers. The low-frequency magnetic susceptibilities of soil and sediment were measured by Bartington MS2 dual-frequency susceptibility meter in a low-frequency $(0.47 \mathrm{kHz})$ magnetic field at $25^{\circ} \mathrm{C}$, and the measured values were recorded. Each sample was tested in triplicates, and the average value was taken as the sample's low-frequency susceptibility value.

\section{RESULTS AND DISCUSSION}

\section{Overall characteristics of magnetic susceptibility}

There are two sources of magnetic minerals in materials. One is exogenous, i.e. from the outside in flowing water or atmosphere; including rock weathering products, industrial "three wastes", domestic refuse, and cosmic dust; and the other is endogenous, i.e. 
Table 1 The magnetic susceptibility of the substrate sludge in different regions.

\begin{tabular}{lcc}
\hline Sampling area & \multicolumn{2}{c}{$\mathrm{X}_{\mathrm{lf}}\left(10^{-8} \mathrm{~m}^{3} / \mathrm{kg}\right)$} \\
\cline { 2 - 3 } & Average & Range \\
\hline Jiuhua Park & 21.52 & $15.57-42.28$ \\
Xiannvshan Farmland & 58.19 & $36.76-71.33$ \\
Yaai Village Farmland & 66.54 & $43.00-83.00$ \\
Juhuatang Park & 103.99 & $68.18-214.74$ \\
Yuhu Park & 118.64 & $86.44-249.23$ \\
Total & 63.92 & $15.57-249.23$ \\
\hline
\end{tabular}

Table 2 The magnetic susceptibility of the surface soil in different regions.

\begin{tabular}{lcc}
\hline Sampling area & \multicolumn{2}{c}{$\mathrm{X}_{\mathrm{lf}}\left(10^{-8} \mathrm{~m}^{3} / \mathrm{kg}\right)$} \\
\cline { 2 - 3 } & Average & Range \\
\hline Jiuhua Park & 25.08 & $12.11-52.63$ \\
Yaai Village Farmland & 30.06 & $8.06-51.86$ \\
Xiannvshan Farmland & 46.14 & $20.46-83.10$ \\
Juhuatang Park & 58.20 & $24.69-97.00$ \\
Yuhu Park & 68.34 & $25.15-132.21$ \\
Total & 48.73 & $8.06-132.21$ \\
\hline
\end{tabular}

secondary magnetic minerals formed by "primary" iron through chemical or biochemical processes [3]. Heavy metals in the sediment of urban lakes/ponds originate from both of the aforementioned sources; but more importantly, heavy metals often accumulate due to urban runoff and various wastewater discharges. The surface soil changes rapidly because of the interference of various external factors, but the substrate sludge is more likely to accumulate various heavy metals for a long time. Consequently, the sludge's accumulated heavy metals pollute the water body and endanger its ecological system and people's health $[30,31]$.

$\mathrm{Be}$ it between regions or between different sampling points in the same region, the variation range of the substrate sludge's magnetic susceptibility was enormous, ranging from $8.06 \times 10^{-8} \mathrm{~m}^{3} / \mathrm{kg}$ to $249.23 \times 10^{-8} \mathrm{~m}^{3} / \mathrm{kg}$, with an average value of $55.81 \times 10^{-8} \mathrm{~m}^{3} / \mathrm{kg}$ (Table 1 ). The magnetic susceptibility of each region from small to large was as follows: Jiuhua Park $<$ Xiannvshan Farmland $<$ Yaai Village Farmland < Juhuatang Park < Yuhu Park.

Jiuhua Park, with a lake located within, is a newly-built urban park. The sediments at the bottom of the lake are mostly primitive soil layers, which are not affected by human factors. The low-frequency magnetic susceptibility of the bottom sludge in the lake was lower than that in the other areas. On the contrary, Yuhu Park lies in the center of the city, surrounded by numerous residential areas, with a massive flow of people and close to the city's main road; so it is severely polluted by living and traffic pollution, which could be the main reason for the high magnetic susceptibility of the substrate sludge in the Park's lake. Juhuatang Park is close to the old industrial zone of Xiangtan City, and the industrial pollution is severe. Therefore, the magnetic susceptibility of the underwater sludge in Juhuatang Park was relatively high. However, in recent years, due to the optimization or halt of the old heavily polluting enterprises in Xiangtan City and the effective treatment of its environmental pollution by Juhuatang Park itself, the pollution was relatively reduced.

Compared with the substrate sludge's magnetic susceptibility, the variation range of the surface soil's magnetic susceptibility was relatively small, but there were still significant changes. The average value of soil magnetic susceptibility was $8.72 \times 10^{-8}$ $\mathrm{m}^{3} / \mathrm{kg}$, which fluctuated from $8.06 \times 10^{-8} \mathrm{~m}^{3} / \mathrm{kg}$ to $132.21 \times 10^{-8} \mathrm{~m}^{3} / \mathrm{kg}$. The magnetic susceptibility of each region from small to large was as follows: Jiuhua Park, Yaai Village Farmland, Xiannvshan Farmland, Juhuatang Park, and Yuhu Park (Table 2).

\section{Characteristics of magnetic susceptibility of substrate sludge and soil in different urban areas}

Sampled lakes lie in different parts of the City, including Urban Area (Yuhu Park and Juhuatang Park), Urban-rural Junction (Jiuhua De Culture Park and Yaai Village Farmland), and Rural Area (Xiannvshan Farmland). Fig. 1 and Fig. 2 are drawn by Golden Software Surfer 11 to clearly compare the variation of soil and sediment's magnetic susceptibility.

\section{Urban area}

The variation of magnetic susceptibility of sediment and surrounding soil in Yuhu Park was the most considerable. The magnetic susceptibility of lake sediment and surface soil in Yuhu Park varied from 86.44 to $249.23 \times 10^{-8} \mathrm{~m}^{3} / \mathrm{kg}$ and 25.15 to $132.21 \times 10^{-8} \mathrm{~m}^{3} / \mathrm{kg}$, with average values of $118.64 \times 10^{-8} \mathrm{~m}^{3} / \mathrm{kg}$ and $68.34 \times 10^{-8} \mathrm{~m}^{3} / \mathrm{kg}$, respectively.

The magnetic susceptibility of the substrate sludge of Yuhu Lake, situated in close proximity to the residential area's center, increased from the southwest to the northeast. Besides, the Middle Lake and the Lower Lake have a larger area and 

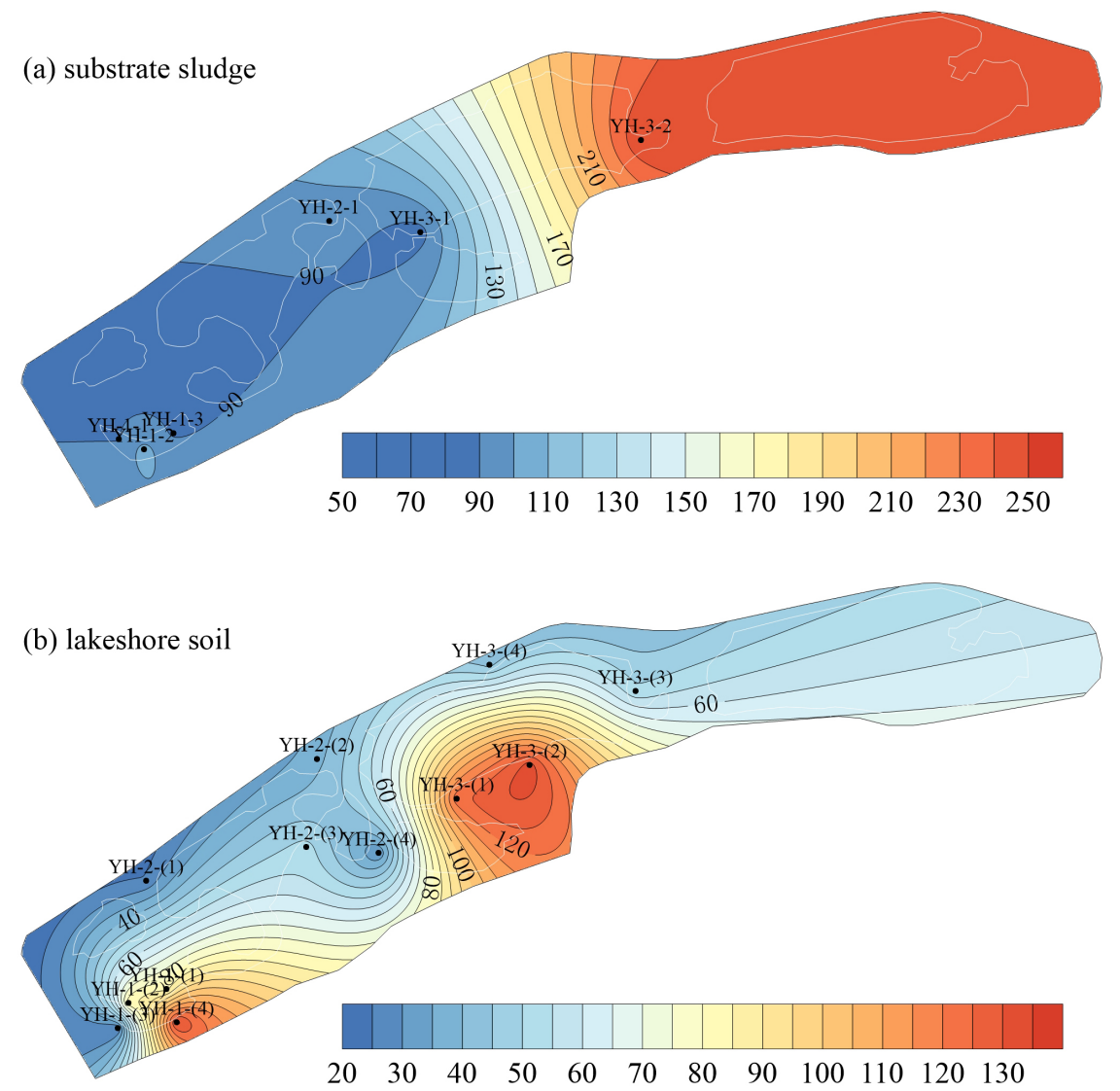

Fig. 1 Distribution of magnetic susceptibility of sediment and soil in Yuhu Park.
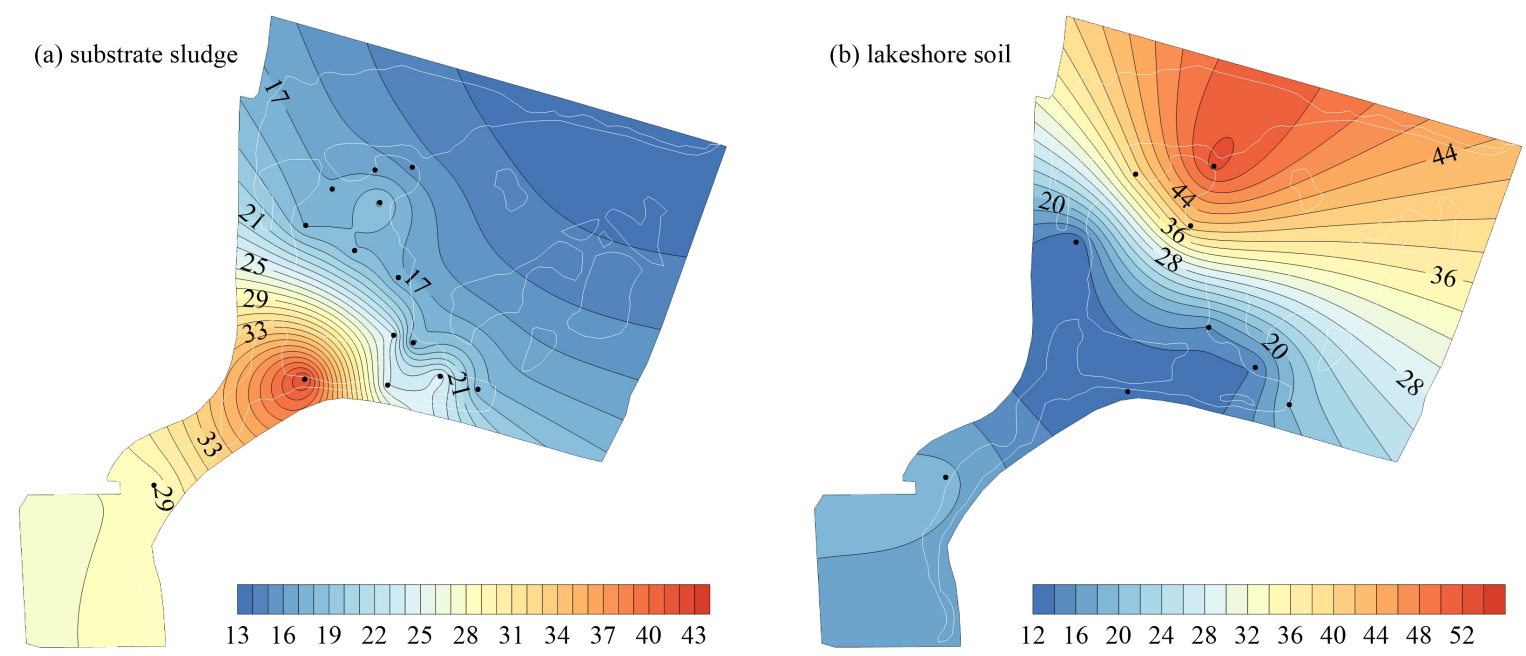

Fig. 2 Distribution of magnetic susceptibility of sediment and soil in Jiuhua De Culture Park.

more massive passenger flow. Therefore, the human impact is severe. At the junction of different lake areas, a large amount of sediment might accumulate due to the slow flow rate; hence high soil magnetic susceptibility was found at these sampling points, such as YH-3-2 $\left(247.37 \times 10^{-8} \mathrm{~m}^{3} / \mathrm{kg}\right)$ (Fig. 1(a)).

The magnetic susceptibilities of $\mathrm{YH}-1-(4)$ $\left(131.47 \times 10^{-8} \mathrm{~m}^{3} / \mathrm{kg}\right), \quad$ YH-3-(1) $\left(123.23 \times 10^{-8}\right.$ 
$\left.\mathrm{m}^{3} / \mathrm{kg}\right)$, and YH-3-(2) (132.21 $\left.\times 10^{-8} \mathrm{~m}^{3} / \mathrm{kg}\right)$ were significantly higher than those of the other sampling points. The main reason was that the aforementioned sampling points were close to the Park's main roads and residential areas, so human activities contributed a significant impact on them and led to the high magnetic susceptibility. However, the magnetic susceptibilities of the other sampling points were significantly lower, such as YH-1-(3) $\left(25.15 \times 10^{-8} \mathrm{~m}^{3} / \mathrm{kg}\right)$, YH-2-(1) $\left(25.88 \times 10^{-8} \mathrm{~m}^{3} / \mathrm{kg}\right)$, and $\mathrm{YH}-2-(4)\left(30.34 \times 10^{-8}\right.$ $\mathrm{m}^{3} / \mathrm{kg}$ ), mainly because the soils at these points lay in the vicinity of shrubs [7] (Fig. 1(b)).

The magnetic susceptibility of sediment in Juhuatang Park rangeed from $68.18 \times 10^{-8} \mathrm{~m}^{3} / \mathrm{kg}$ to $214.73 \times 10^{-8} \mathrm{~m}^{3} / \mathrm{kg}$, with an average of $103.99 \times 10^{-8} \mathrm{~m}^{3} / \mathrm{kg}$. The magnetic susceptibility of soil ranges from $24.69 \times 10^{-8} \mathrm{~m}^{3} / \mathrm{kg}$ to $96.99 \times 10^{-8}$ $\mathrm{m}^{3} / \mathrm{kg}$, with an average of $58.19 \times 10^{-8} \mathrm{~m}^{3} / \mathrm{kg}$. Juhuatang Park is located on the west side of Dongsi Road in Xiangtan City. In the Park, there are various sports facilities, cruise boats, tea houses, and barbecue grounds. Moreover, there are many commercial shops and residential areas nearby the Park. In the southwest direction, there are also some processing plants of Xiangtan Iron \& Steel Co. LTD. of Hunan Valin. These might be the reasons for its high magnetic susceptibility.

\section{Urban-rural junction}

The magnetic susceptibility of sediment in Jiuhua De Culture Park ranges from $15.57 \times 10^{-8} \mathrm{~m}^{3} / \mathrm{kg}$ to $42.28 \times 10^{-8} \mathrm{~m}^{3} / \mathrm{kg}$, with an average of $21.52 \times 10^{-8}$ $\mathrm{m}^{3} / \mathrm{kg}$. The magnetic susceptibility of soil ranges from $12.11 \times 10^{-8} \mathrm{~m}^{3} / \mathrm{kg}$ to $52.63 \times 10^{-8} \mathrm{~m}^{3} / \mathrm{kg}$, with an average of $25.08 \times 10^{-8} \mathrm{~m}^{3} / \mathrm{kg}$. The Park covers a large area with abundant waterscape resources. There are many commercial residences around the scenic spot. The spatial variation of magnetic susceptibility is complex (Fig. 2). Generally speaking, the overall magnetic susceptibility is low, which may be related to that the Park is located in the new development zone and is disturbed by human activities for a short time.

Yaai Village Farmland's sampling point is near the campus of Hunan University of Science and Technology and the Shanghai-Kunming Expressway, beside which there is farmland. The sediment's magnetic susceptibility in Yaai Village Farmland ranges from $43.00 \times 10^{-8} \mathrm{~m}^{3} / \mathrm{kg}$ to $83.00 \times 10^{-8}$ $\mathrm{m}^{3} / \mathrm{kg}$, with an average of $66.54 \times 10^{-8} \mathrm{~m}^{3} / \mathrm{kg}$. The sediment's magnetic susceptibility in Yaai Village Farmland ranges from $8.06 \times 10^{-8} \mathrm{~m}^{3} / \mathrm{kg}$ to
$51.86 \times 10^{-8} \mathrm{~m}^{3} / \mathrm{kg}$, with an average of $30.06 \times 10^{-8}$ $\mathrm{m}^{3} / \mathrm{kg}$. This area's magnetic susceptibility value is lower than that of many other areas, which may be due to its distance from the urban area and its proximity to farmland.

\section{Rural area}

Because the Xiannvshan Farmland is far away from the urban area, its magnetic susceptibility value was low. The average magnetic susceptibility of sediment in Xiannvshan Farmland was $58.19 \times 10^{-8}$ $\mathrm{m}^{3} / \mathrm{kg}$, and the average magnetic susceptibility of surrounding soil was $46.14 \times 10^{-8} \mathrm{~m}^{3} / \mathrm{kg}$. However, the excessive agricultural activities and nearby highway transportation kept their magnetic susceptibility at a certain level, not the lowest in all of the studied areas.

\section{Spatial configuration relations and discussion}

Based on lake sediment and surrounding soil's magnetic susceptibility data, this study explored the spatial distribution of lake sediment magnetic susceptibility and its possible collocation with other factors by taking Xiangtan typical parks as examples.

Yuhu Park, founded in 1954, lies in the center of Xiangtan City and covers an area of 12 hectares, including Upper Lake, Middle Lake, and Lower Lake. Jiuhua Park, founded in 2011, lies in the central area of Jiuhua Binjiang New Town, with an area of about 66.67 hectares, including about 40 hectares of water area. It is adjacent to ShanghaiKunming Expressway in the north and Xuefu Road in the south (Fig. S1). Both parks have large water storage areas, typical representatives of new and old parks, and urban and suburban parks. In this study, only these two parks were discussed and not the other sampling areas because of their small water bodies.

The magnetic susceptibility of soil around Yuhu Park showed two high-value centers, and one lowvalue center was shown in the sediment. From the spatial distribution of high and low-value centers, the locations were relatively close, indicating that the change of magnetic susceptibility of lake sediment was affected by the lakeshore soil. The soil could be the dominant factor in the variation of magnetic susceptibility of the Yuhu Park's substrate sludge. However, the locations of high and low susceptibility centers of the lakeshore soil and the substrate sludge did not entirely coincide with each other, which might be related to lake water movement, lake ecosystem, and even artificial siltation removal. 


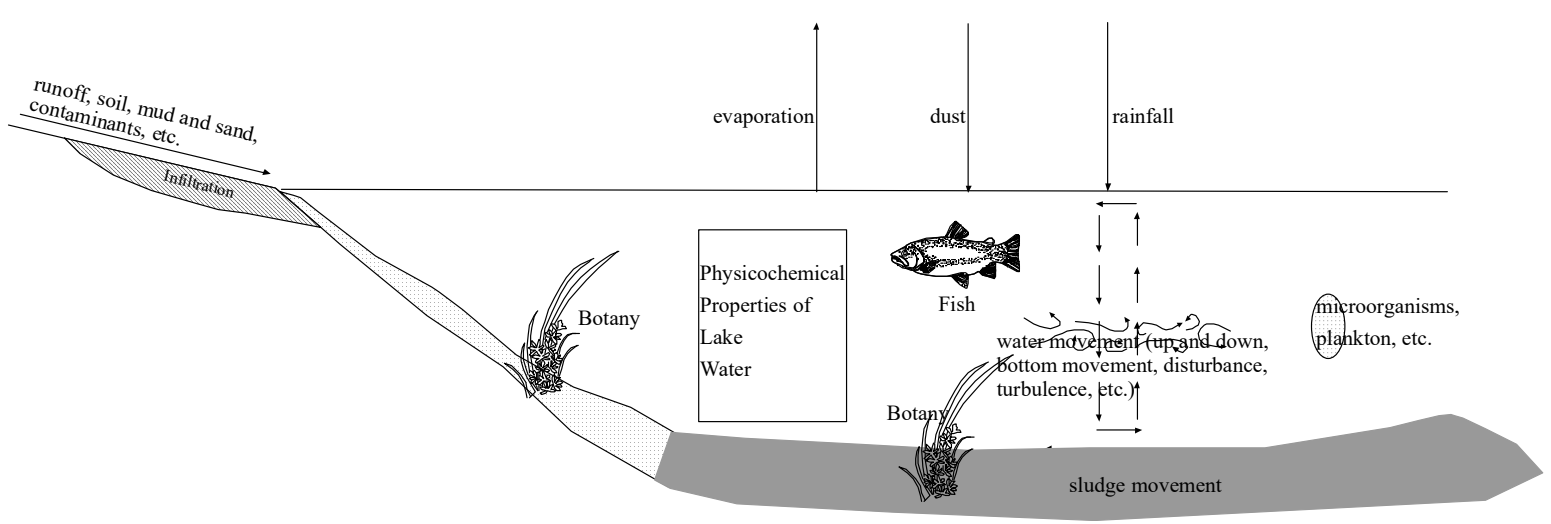

Fig. 3 Sources and influencing factors of heavy metals in lake sediment.

The variation of magnetic susceptibilities of lakeshore soil and lake sediment of the Jiuhua Park was rather complicated. The spatial locations of the high and low magnetic susceptibility centers of the sediment and the soil were quite different. The high-value area of magnetic susceptibility of substrate sludge lay in the low-value area of magnetic susceptibility of the surrounding soil, while the lowvalue area of magnetic susceptibility of substrate sludge lay in the high-value area of surrounding soil magnetic susceptibility. This configuration was quite different from the Yuhu Park's. The reason might be closely related to the Park's lake area and shape. Because the open area of Yuhu Park is small, and the shapes of the Park and the lake are long and narrow, the surrounding soil would enter the water body immediately under runoff. Moreover, the transport capacity of the lake water could be weaker due to its smaller area. Therefore, the high and low magnetic susceptibility values of sediment and soil were close in space.

However, Jiuhua Park's lake area is large, and the ability of lake water movement is strong, resulting in significant regional differences. Simultaneously, the high-value area of the substrate sludge's magnetic susceptibility in Jiuhua Park was located in the narrowest location of the lake. The long and narrow channel was beneficial to sediment accumulation but not to diffusion. Numerous magnetic materials accumulated at the channel, resulting in high magnetic susceptibility of sediment. Besides, the Park is located adjacent to a construction site, and magnetic materials produced in the construction process also enter the waterway under the runoff, which could be one reason for the sediment's high magnetic susceptibility value. From this point of view, the change of lake sediment's magnetic sus- ceptibility could be affected by many factors, such as the shape of the lake, the strength of water flow, the intensity of human activities, the construction process, and the types of factories and enterprises $[32,33]$.

The magnetic susceptibility of lake sediment, which reflects the accumulation and transformation of heavy metals, is an indicator of heavy metal pollution in lakes. Although the application of environmental magnetic methods to the study of heavy metal pollution in river sediments is relatively rare [34], a large number of studies have shown that there is a significant correlation between the magnetic characteristics of soil and sediment and heavy metal pollution, which can reflect the degree of heavy metal pollution [35-38]. For urban rivers, due to their relatively closed environmental conditions, their self-purification capacity and water renewal speed are far less than those of large rivers, so they are more vulnerable to the impact of coastal pollutant emissions [39]. As far as this study is concerned, urban lakes/ponds' environmental conditions are more closed and more affected by coastal pollutants. Some pollutants, including heavy metals, are transferred into sediment and stored under specific conditions, which is very easy to cause secondary pollution to the water body [40]. The sources of heavy metals in lake sediment are very complex, and the physical and chemical processes of their accumulation and transformation are also very complex (Fig. 3). Influenced by lake water's movement, aquatic ecosystem, physical and chemical properties of lake water, the distribution of heavy metals in lakes is not uniform $[41,42]$. This nonuniform distribution is not static and will change under certain conditions with very complicated factors [43-45]. The changes of heavy metal content in the 
sediment affect the changes and safety of the whole water ecosystem.

\section{CONCLUSION}

The results showed that the low-frequency magnetic susceptibility of substrate sludge in Xiangtan City fluctuated widely. The soil's magnetic susceptibility was lower than the substrate sludge's. The magnetic susceptibility of substrate sludge increased gradually from the suburb to the urban areas, reflecting the significant influence of human activities.

Many factors, such as the shape of the lake, the strength of the current, the movement of the lake water, the aquatic ecosystem, the physical and chemical properties of the lake water, the intensity of human activities, the construction of buildings, and the types of factories and enterprises, could affect the changes of the magnetic susceptibility of lake sediment, revealing the changes of heavy metals in the lake. Therefore, more detailed studies are needed to reveal the law of change.

\section{Appendix A. Supplementary data}

Supplementary data associated with this article can be found at http://dx.doi.org/10.2306/ scienceasia1513-1874.2021.048.

Acknowledgements: We thank Zhou Ye, Liu Fengying, Zhang Xiaoliang, Li Yingying, Li Ying, and Wang Ruofei for their help in field measurements and magnetic susceptibility analyses.

\section{REFERENCES}

1. Yang P, Byrne JM, Li H, Shao HB (2016) Evaluation of semi-arid arable soil heavy metal pollution by magnetic susceptibility in the Linfen basin of China. Arid Land Res Manag 30, 258-268.

2. Xiong DG (1991) Analyses of the current of Poyang Lake. Oceanol Limnol Sin 3, 200-207.

3. Devanesan E, Chandrasekaran A, Sivakumar S, Joy KF, Najam LA, Ravisankar R (2020) Magnetic susceptibility as proxy for heavy metal pollution detection in sediment. Iran J Sci Technol A 44, 875-888.

4. Wang G, Liu Y, Chen J, Ren FF, Chen YY, Ye FZ, Zhang WG (2018) Magnetic evidence for heavy metal pollution of topsoil in Shanghai, China. Front Earth Sci 12, 125-133.

5. Gautam P, Blaha U, Appel E (2005) Integration of magnetism and heavy metal chemistry of soils to quantify the environmental pollution in Kathmandu, Nepal. Isl Arc 14, 424-435.

6. Li S, Hu XF, Du Y, Jiang Q, Li Y, Feng JW, Wang JG (2012) Spatial variation of magnetic intensity of topsoils in Jiading District, Shanghai and its environmental implication. Acta Pedol Sin 49, 9-17.
7. Liu DX, Ma JH, Sun YL, Li YM (2016) Spatial distribution of soil magnetic susceptibility and correlation with heavy metal pollution in Kaifeng City, China. Catena 139, 53-60.

8. Karimi R, Ayoubi S, Jalalian A, Sheikh-Hosseini AR, Afyuni M (2011) Relationships between magnetic susceptibility and heavy metals in urban topsoils in the arid region of Isfahan, central Iran. $J$ Appl Geophys 74, 1-7.

9. Ayoubi S, Karami M (2019) Pedotransfer functions for predicting heavy metals in natural soils using magnetic measures and soil properties. $J$ Geochem Explor 197, 212-219.

10. Zhao SS, Wang YH (2016) The soil magnetic susceptibility, heavy metal characteristics and correlation analysis in the Xiaerxili. Soils 48, 1179-1187.

11. Ayoubi S, Adman V, Yousefifard M (2019) Efficacy of magnetic susceptibility technique to estimate metal concentration in some igneous rocks. Model Earth Syst Environ 5, 1743-1750.

12. Yang PG, Ge J, Yang M (2017) Identification of heavy metal pollution derived from traffic in roadside soil using magnetic susceptibility. B Environ Contam Tox 98, 837-844.

13. Mullins CE (1977) Magnetic susceptibility of the soil and its significance in soil science: A review. Eur $J$ Soil Sci 28, 223-246.

14. Wang XS (2013) Assessment of heavy metal pollution in Xuzhou urban topsoils by magnetic susceptibility measurements. J Appl Geophys 92, 76-83.

15. Lu Y, Gong ZT, Zhang GL (2001) The magnetic susceptibility characteristic of urban soil and its environmental significance. $J$ South China Agric Univ 22, 26-28.

16. Naimi S, Ayoubi S (2013) Vertical and horizontal distribution of magnetic susceptibility and metal contents in an industrial district of central Iran. $J$ Appl Geophys 96, 55-66.

17. Ayoubi S, Jabbari M, Khademi H (2018) Multiple linear modeling between soil properties, magnetic susceptibility and heavy metals in various land uses. Model Earth Syst Environ 4, 579-589.

18. Zhang T, Liu S, Song YM, Pan JC, Guo PR (2019) Bioavailability and ecological risk assessment of heavy metals in sediments of marine aquaculture in Zhelin Bay. Acta Sci Circumst 39, 706-715.

19. Al-Hagara OE, Bayoumib RA, Azizd OAA, Mousad AM (2020) Biosorption and adsorption of some heavy metals by Fusarium sp. F6c isolate as affected by gamma irradiation and agricultural wastes. ScienceAsia 46, 37-45.

20. Suwanpraserta S, Saenphetb S, Buncharoenb W, Kullasootc S, Sareeinc N, Phalarakshb C (2020) Effects of cadmium on acetylcholinesterase activities and histopathology of African catfish (Clarias gariepinus) from contaminated fish farm in Mae Sot District, Tak Province, Thailand. ScienceAsia 46, 611-618. 
21. McQuillan JS, Kille P, Powell K, Galloway TS (2014) The regulation of copper stress response genes in the polychaete nereis diversicolor during prolonged extreme copper contamination. Environ Sci Technol 48, 13085-13092.

22. Ma XY, Yang H, Yao X, Zhao QG, Xie B, Zheng J, Chen YZ (2016) Heavy metal concentration of artificial lake for aquaculture and its health effect on surrounding residents: A case study in Suya Lake. Acta Sci Circumst 36, 2281-2289.

23. Ginsberg GL, Toal BF (2009) Quantitative approach for incorporating methylmercury risks and omega3 fatty acid benefits in developing species-specific fish consumption advice. Environ Health Persp 117, 267-275.

24. Yi YJ, Yang ZF, Zhang SH (2011) Ecological risk assessment of heavy metals in sediment and human health risk assessment of heavy metals in fishes in the middle and lower reaches of the Yangtze River basin. Environ Pollut 159, 2575-2585.

25. Diao ZH, Shi TH, Wang SZ, Huang XF, Zhang T, Tang YT, Zhang XY, Qiu RL (2013) Silane-based coatings on the pyrite for remediation of acid mine drainage. Water Res 47, 4391-4402.

26. Wang XH, Shan BQ, Tang WZ, Zhang WQ, Yang L (2016) Pollution characteristics and ecological risk of mercury in the surface sediment of a typical urban river. Acta Sci Circumst 36, 1153-1159.

27. Pruden A (2014) Balancing water sustainability and public health goals in the face of growing concerns about antibiotic resistance. Environ Sci Technol 48, 5-14.

28. Zhang Y, Xiang YB, Chen WY (2019) Heavy metal content in the bark of Camphora tree in Xiangtan and its environmental significance. Appl Ecol Env Res 17, 9827-9835.

29. Zhang Y, Su JK, Jiang WL, Huang ZL, Xiang YB, Zeng FD (2012) Study on the heavy metal pollution evaluation and countermeasures of middle size and small cities in typical drainage area - Taking Xiangtan Reach of Xiangjiang River as an example. Res $J$ Chem Environ 16, 172-179.

30. Ren J, Shang Z, Tao L, Wang X (2015) Multivariate analysis and heavy metals pollution evaluation in Yellow River surface sediments. Pol $J$ Environ Stud 24, 1041-1048.

31. Ramamoorthy S, Rust BR (1978) Heavy metal exchange processes in sediment-water systems. Environ Geol 2, 165-172.

32. Xie YN, OuYang MF, Huang DZ, Ou FP, Tian Q, Zhang Y, Yin YY, Liu Y (2017) Pollution characteristics, sources and ecological risk of heavy metals in sediments from Dongting lake and its lake inlets. Environ
Chem 36, 2253-2264.

33. Liang J, Liu JY, Yuan XZ, Zeng GM, Lai X, Li XD, Wu HP, Yuan YJ, et al (2015) Spatial and temporal variation of heavy metal risk and source in sediments of Dongting Lake wetland, mid-south China. J Environ Sci Heal A 50, 100-108.

34. Botsou F, Karageorgis AP, Dassenakis E, Scoullos M (2011) Assessment of heavy metal contamination and mineral magnetic characterization of the Asopos River sediments (Central Greece). Mar Pollut Bull 62, 547-563.

35. Ju YT, Wang SH, Zhang QP, Wang L, Deng CL (2004) Mineral magnetic properties of polluted topsoils: A case study in Sanming City, Fujian Province, Southeast China. Chin J Geophys CH 47, 282-288.

36. Li XQ, Hu XF, Sun WM, Zhang GL (2006) Magnetic techniques used for monitoring urban soil pollution. Soils 38, 66-74.

37. Shen MJ, Hu SY, Blaha U, Yan HT, RÃüsler W, Hoffmann V (2006) A magnetic study of a polluted soil profile at the Shijingshan industrial area, Western Beijing, China. Chin J Geophys CH 49, 1665-1673.

38. Dong Y, Zhang WG, Qian P, Jiang QF, Liu Y, Dong CY (2012) Magnetic analysis of heavy metal pollution in Rengang River sediments, Nantong, China. Acta Scien Circum 32, 696-705.

39. Jiang QF, You Z, Ni LM, Qian P (2010) Pollution and potential ecological risk assessment of heavy metals in river sediments of Nantong. Water Resour Prot 26, 11-15.

40. Muller I, Pluquet E (1998) Immobilization of heavy metals in sediment dredged from a seaport by iron bearing materials. Water Sci Technol 37, 379-386.

41. Zhu GW, Qin BQ, Gao G, Luo LC, Wang WM (2005) Accumulation characteristics of heavy metals in the sediments of Lake Taihu, China. J Lake Sci 17, 143-150.

42. Wang H, Wang CX, Wang ZJ (2002) Speciations of heavy metals in surface sediment of Taihu Lake. Environ Chem 21, 430-435.

43. Wu J, Duan DP, Lu J, Luo YM, Wen XH, Guo XY, Boman BJ (2016) Inorganic pollution around the Qinghai-Tibet Plateau: An overview of the current observations. Sci Total Environ 550, 628-636.

44. Yang HD, Battarbee RW, Turner SD, Rose NL, Derwent RG, Wu GJ, Yang RQ (2010) Historical reconstruction of mercury pollution across the Tibetan Plateau using lake sediments. Environ Sci Technol 44, 2918-2924.

45. Li CL, Kang SC, Chen PF, Zhang QG, Mi J, Gao SP, Sillanpää M (2014) Geothermal spring causes arsenic contamination in river waters of the southern Tibetan Plateau, China. Environ Earth Sci 71, 4143-4148. 


\section{Appendix A. Supplementary data}

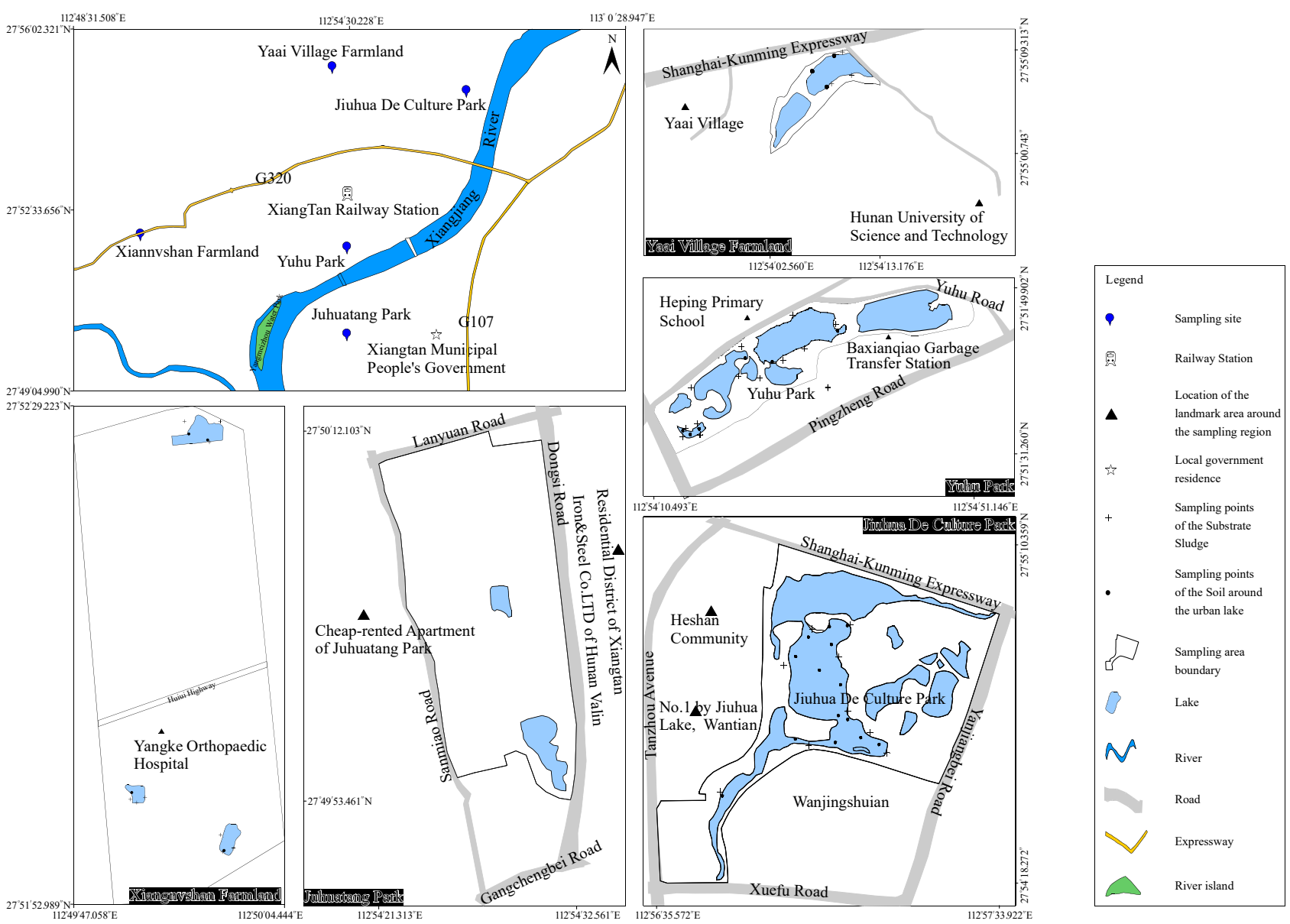

Fig. S1 Distribution of sampling points. 